\title{
Pure oxygen ventilation during general anaesthesia does not result in increased postoperative respiratory morbidity but decreases surgical site infection. An observational clinical study
}

Background: Pure oxygen ventilation during anaesthesia is debatable, as it may lead to development of atelectasis. Rationale of the study was to demonstrate the harmlessness of ventilation with pure oxygen. Methods: This is a single-centre, one-department observational trial. Prospectively collectedroutine-data of 76,784 patients undergoing general, gynaecological, orthopaedic, and vascular surgery during $1995-2009$ were retrospectively analysed. Postoperative hypoxia, unplanned ICU-admission, surgical site infection (SSI), postoperative nausea and vomiting (PONV), and hospital mortality were continuously recorded. During 1996 the anaesthetic ventilation for all patients was changed from 30\% oxygen plus $70 \%$ nitrous oxide to $100 \%$ oxygen in low-flow mode. Therefore, in order to minimize the potential of confounding due to a variety of treatments being used, we directly compared years 1995 (30\% oxygen) and 1997 (100\%), whereas the period 1998 to 2009 is simply described. Results: Comparing 1995 to 1997 pure oxygen ventilation led to a decreased incidence of postoperative hypoxic events (4.3 to $3.0 \% ; p<0.0001)$ and hospital mortality (2.1 to $1.6 \% ; p=0.088)$ as well as SSI (8.0 to $5.0 \% ; p<0.0001)$ and PONV (21.6 to $17.5 \% ; p<0.0001)$. There was no effect on unplanned ICU-admission (1.1 to $0.9 ; p=0.18)$. Conclusions: The observed effects may be partly due to pure oxygen ventilation, abandonment of nitrous oxide, and application of low-flow anesthesia. Pure oxygen ventilation during general anaesthesia is harmless, as long as certain standards are adhered to. It makes anaesthesia simpler and safer and may reduce clinical morbidity, such as postoperative hypoxia and surgical site infection. 
1 Pure oxygen ventilation during general anaesthesia does not result in increased 2 postoperative respiratory morbidity but decreases surgical site infection. An observational 3 clinical study.

4 Benno von Bormann, Sirilak Suksompong, Jürgen Weiler ${ }^{1}$, Rolf Zander ${ }^{2}$

5 Department of Anesthesiology, Siriraj Hospital, Mahidol-University, 2 Prannok Road, 6 Bangkoknoi, Bangkok 10700, Thailand

7 Corresponding Author: Benno von Bormann, Department of Anesthesiology, Siriraj Hospital, 8 Mahidol-University, 2 Prannok Road, Bangkoknoi, Bangkok 10700, Thailand; Phone 9 0066(0)891598442 (mobile), $0066(0) 24197990$ (Office), Fax 0066(0)24113256 (Office), Email:

10 bvb@jodu.de

11 Anästhesie Team Nordrhein, Dinslaken, Germany; Email: juergen.weiler@narkose.de, ${ }^{2}$ 12 Department of Physiology, Johannes Guttenberg-University, Saarstraße 21, D-55122 Mainz, 13 Germany; Email: zander@physioklin.de 
Introduction

15 Abandoning nitrous oxide for general anaesthesia enables the risk-free performance of low flow

16 anaesthesia (1), and as a consequence the oxygen fraction during anaesthetic ventilation $\left(\mathrm{FiO}_{2}\right)$ is

17 an increasingly debated issue (2). Ventilating patients by using a closed circuit ensures that the

18 lowest possible flow corresponds with the oxygen uptake of the individual; which is $200-300$

$19 \mathrm{ml} / \mathrm{min}$ for an adult (3). Applying consequent low flow ventilation has been the key reason for the

20 paradigm change of our department as described in this study; abandoning nitrous oxide was a

21 by-product of this strategy.

22 There is concern about high oxygen fraction deteriorating pulmonary function, as it is known to 23 promote the development of atelectasis (4). However, up to now there is no scientific evidence of

24 this effect being relevant for general anaesthesia in otherwise adequately treated patients (5).

25 The rationale of our study was to demonstrate the harmlessness of pure oxygen ventilation, after

26 realizing that it is still 1. controversially debated (6), 2. not recommended (7) and 3. as far as we 27 know nowhere else routinely applied. Our study, which may be the first of its kind, reports the 28 experience of more than 13 years after switching from $30 \%$ oxygen plus $70 \% \mathrm{~N}_{2} \mathrm{O}$ ventilation to $29100 \%$ oxygen. 


\section{METHODS}

31 Comprehensive data analysis was started after ethical approval was granted by the Siriraj 32 Institutional Review Board (Si 202/2013; 158/2556/E4). The data were collected at the Catholic 33 Clinic Duisburg, now Helios-Klinikum Duisburg, Germany; their use was granted by the General 34 Manager, according to the letter dated October 22, 2012.

Patients: Patients with general, vascular, orthopaedic and gynaecological surgery under general anaesthesia between 01.01.1995 and 31.12.2009 except premature infants were included. There were no other exclusion criteria.

Study questions: First, does pure oxygen ventilation affect the incidence of clinically relevant postoperative respiratory problems (oxygenation) and unplanned admission to the Intensive Care Unit (ICU)? Additionally, does pure oxygen ventilation decrease surgical site infection (SSI) and does it influence postoperative nausea and vomiting (PONV); is there an effect on hospital mortality?

\section{Change to pure oxygen and data collection}

Until 1996 anaesthetic ventilation in our department comprised 70\% nitrous oxide plus 30\% oxygen $\left(\mathrm{FiO}_{2}=0.3\right)$. In preparation for a fundamental change of the ventilation strategy, meticulous data collection as described below was started $1^{\text {st }}$ January 1995 , the last complete year with 30\% oxygen ventilation. In January 1996 a testing phase was started with varying anaesthetic ventilation, $100 \%$ oxygen vs. $30 \%$ oxygen $+70 \%$ nitrous oxide. Upon completion, data analysis showed no negative clinical outcomes, particularly no respiratory problems after high oxygen ventilation. The final decision to switch to pure oxygen was made in August 1996. Through SOP (standard operating procedure) No 1.2.1/96 pure oxygen ventilation was mandated for all patients with general anaesthesia. Details of anaesthetic treatment during 1995 and from August 1996 to 2009 are summarized in table 1. Figure 1 shows the original display of a ventilator during low flow pure oxygen ventilation (Primus ${ }^{\mathrm{TM}}$, Dräger AG, Lübeck, Germany) in 1997.

Data were recorded by the anaesthesiologists responsible, residents, staff members, senior consultants, and head of department respectively using adapted forms. Central documentation and maintenance of data was performed by the head of the department and one of the senior consultants $(\mathrm{JW})$. Patients' data were kept confidential until discharge or death, and then 
64.

62.

68.

condensed and transferred into anonymous files without traceable personal characteristics. These files summarize parameters as described below.

\section{Parameters and organization}

The following parameters in summarized pattern have been available for evaluation: Patient's age $(0-15,16-70,>70$ years old $)$, female gender, ASA risk classification (I + II, III, IV) following the modified score of Lutz et al. (8), regional pain catheter (yes/no), homologous and/or autologous blood transfusion (yes/no), operation time $(\leq 90,>90$ minutes).

Surgical intervention - accurately defined groups (s. table 2 and results).

Postoperative hypoxia (up to 24 hours postoperatively) defined as $\mathrm{O}_{2}$-Sat $<92 \%$ while breathing normal air without spontaneous recovery and the need for treatment, such as supplemental oxygen and/or CPAP assistance.

Unplanned ICU-admission during hospital stay. This group include patients with severe pulmonary complications after surgery.

Surgical site infection (SSI), defined as wound infection during hospital stay with at least positive bacterial culture after smear test. The information was gained from surgeons and/or ward staff members on the occasion of daily contacts. Cooperation was undisturbed.

Postoperative nausea and/or vomiting (PONV; up to 24 hours postoperatively) without differentiation between nausea and vomiting. It was estimated positive the patients judging it as 'very unpleasant'.

Hospital mortality; no follow up after discharge.

All operations with general anaesthesia were performed in a central area with 7 ORs plus $7+7$ connected areas for anaesthesia care. Directly connected to the ORs were the postoperative Care Unit (PACU) with 6 beds and the Intensive care unit (ICU) with 12 beds, both run by the anaesthetic department. Patients not scheduled for ICU were postoperatively moved to PACU (all). Oxygen $2-41 / \mathrm{min}$ was applied via nasal tube, which was continued on the ward until the $1^{\text {st }}$ postoperative day and beyond at treating surgeons' discretion. All patients have been visited by 'their' anaesthesiologist on postoperative day one and again if appropriate. Crucial documentation, including the pre- and postoperative period was under permanent scrutiny by senior staff members and the head of department. Every single protocol had to be signed by the department head or his proxy before filing. 


\section{$90 \quad$ Statistical analysis}

91 Due to confounding factors data of the whole 15-years investigation period were not statistically 92 evaluated but described in absolute numbers and/or percentages only. The well matching years 931995 (30\% oxygen) and 1997 (100\% oxygen) were compared applying statistical measures.

94 Comparing 1995 and 1997: Sample size calculation was based on surgical site infection rate in 95 patients receiving $30 \%$ oxygen during general anaesthesia. According to the literature 96 supplemental oxygen may lead to an approximate decrease of SSI between 25 and 50\% (9,10). It 97 was assumed patients with $30 \%$ compared to $100 \%$ oxygen ventilation during general anaesthesia 98 will have a $20 \%$ higher rate of infection. To detect a type I error of 0.05 and a type II error of 0.1 99 using nQuery Advisor 3.0 the required sample size in each group is 5,241.

100 Data were analysed using SPSS version 16.0 software (SPSS, Inc., Chicago, IL, USA). 101 Categorical data such as sex, ASA physical status, prevalence of pain therapy, transfusion rate 102 and incidence of side effects are presented as number (per cent) and compared using $\chi 2$ test. A p103 value less than 0.05 was considered statistically significant. 


\section{RESULTS}

A total of 76,784 patients with general anaesthesia during 1995 - 2009 (15 years) are included, 66,226 of them (1997 - 2009) having received pure oxygen ventilation.

\section{From 1995 to 2009}

Age groups $0-15,16-70$, and $>70$ years: There was a slight increase of patients $>70$ in all groups, most pronounced in vascular surgery.

Gender: The ratio of female patients didn't change significantly during the years, which was similar for the risk status (ASA score); only in gynaecological patients the rate of ASA III/IVpatients increased from below $20 \%$ in 1995 , to nearly $40 \%$ in 2009.

Pain Catheters: The rate of pain catheters applied in patients with general surgery was about $30 \%$ with little observed variation over the years; in gynaecology it was $6-10 \%$, in orthopaedics and trauma $22-29 \%$, and in vascular patients $23-27 \%$.

Homologous blood transfusion (HT): The most frequent transfusions were red cells (OR, ICU, wards). The HT-rate was $16.7-25.4 \%$ in general surgery, $6.2-12.8 \%$ in gynaecology, $9.6-$ $20.4 \%$ in orthopaedic surgery, and $12.6-18.4 \%$ in vascular surgery.

Autologous blood transfusion (AT): Most patients with AT were in vascular (up to 40.4\%) and orthopaedic surgery (up to $34 \%$ ), due to frequent autologous predeposit.

Operation time: In general-, orthopaedic- and vascular-surgery the relation $\leq 1.5 \mathrm{~h}:>1.5 \mathrm{~h}$ was about 50:50 - 45:65 with no relevant changes during the years. In gynaecological patients the ratio was 58:52 - 70:30.

Outcome: Including all surgical patients postoperative hypoxia, surgical site infection (SSI) and postoperative nausea and vomiting (PONV) dropped significantly from 1995 to 1997 with a decreasing tendency during the years to follow, whereas unplanned ICU-admission and hospitalmortality remained to a large extent stable.

Figure 2, shows the outcome of all patients independent from surgical speciality regarding the observed five parameters. Including all 4 investigated surgical disciplines Figure 3 and 4 show the incidence of postoperative hypoxia and the incidence of surgical site infection (SSI) respectively. 
Group characteristics: With exception of increase of elderly ( $>70$ years) from $8.9 \%$ (1995) to 14.0\% (1997) in the vascular group, there were no significant differences between 1995 and 1997 regarding surgical procedures (Table 2), patient's age, gender, ASA status, pain management, and transfusion requirement (Table 3).

Outcome: The incidences of the five recorded parameters are demonstrated in Table 4.

Postoperative Hypoxia: Pure oxygen ventilation led to a decrease of postoperative hypoxia in all groups and subgroups, which was significant in all patients $(4.3 \%$ to $3.0 \%$; p $<0.0001)$, in patients with general surgery (all; $p=0.026)$, in orthopaedic patients (all; $p=0.003$ ), and in arthroplasty patients $(\mathrm{p}=0.020)$. There was no report of atelectasis related hypoxemia.

Unexpected ICU-admission (U-ICU): the frequency of U-ICU was generally low with no significant changes between 1995 and 1997.

Surgical site infection (SSI): Comparing all patients without dividing in surgical groups or subgroups SSI decreased from 8\% in 1995 to 5\% in $1997(\mathrm{p}<0.0001)$, and decreased also within all subgroups which was statistically significant in general surgery, and in patients with peripheral artery surgery (Table 4).

Postoperative nausea and vomiting (PONV): Decrease of PONV was significant for all patients, all surgical disciplines in total, and some subgroups, such as minor general and minor orthopaedic surgery and patients with operations of the peripheral arteries.

Mortality: Overall Hospital mortality dropped from $2.1 \%$ to $1.6 \%(\mathrm{p}=0.088)$. There were no significant differences within the subgroups.

\section{DISCUSSION}

Findings: We found that high oxygen ratio leads to a decrease of postoperative hypoxia and overall in-hospital mortality as well as a reduction of surgical site infection and postoperative nausea and vomiting. There were no adverse effects.

Data quality and clinical standards: This single-centre study analysed follow-up routine data, which were steadily and prospectively collected in a well manageable and tightly organized anaesthetic division. Initially publication was not planned; therefore patients consent had not to be obtained. Because data generally belong to the respective hospital, their use had to be granted by the general manager, which was done with letter from October 2012. 
162 It is known that quality of anaesthetic management, such as preoperative antibiotics, maintenance 163 of perioperative normothermia and optimized pain therapy relevantly affect patients' outcome 164 (11). In our Department quality standards (SOP) have been implemented since 1989, which is 165 long before acquisition of the presented data. Almost all of our patients, when indicated had 166 regional pain catheters. Transfusions, known to deteriorate surgical patients' outcome (12), were 167 standardized by specific mandatory transfusion instructions (13). Red cells were given when $\mathrm{cHb}$ 168 was $<8.0$ (homologous) or $<9.0 \mathrm{~g} / \mathrm{dl}$ (autologous) respectively. All patients, even for the shortest surgical procedure were provided with a warming blanket which included the postoperative period when necessary. The consistency of anaesthetic management is demonstrated in table 1 . The influence of the individual anaesthesiologist on outcome is considered to be limited. Tables 2 (surgical procedures) and 3 (group characteristics) show the comparability of the data 1995 vs. 1997, which is in accordance with the Statistical Department, Mahidol University.

Confounding factors: Within 15 years surgical techniques and hygiene standards improved markedly, and so did equipment and performance in anaesthesia and intensive care. In 1997 the mean operation time for total hip arthroplasty in our hospital was 2 hours 30 minutes, the average blood loss 1,000 $\mathrm{ml}$ and transfusion requirement (autologous and/or homologous) 100\%. In 2000 with a new orthopaedic crew it was 45 minutes, $150 \mathrm{ml}$ and 35\% (almost entirely autologous) respectively. Between 1995 and 2009 the chairmen of all surgical disciplines included in this data collection changed. Only the head of anaesthesia (BvB) remained the same. However, assessing our data we have to include not only pure oxygen ventilation strategy but also ventilating in lowflow instead of high-flow mode and using nitrous oxide plus oxygen or oxygen alone.

Low flow ventilation. Though the flow during anesthetic ventilation does not influence tidal volume or endexpiratory pressure, there is a significant effect on lung function and -integrity. Bilgi et al. (14) in their clinical study compared $1 \mathrm{~L} / \mathrm{min}$ ventilation during anesthesia with $3 \mathrm{~L} / \mathrm{min}$ in otherwise healthy individuals. They found that respiratory function and mucociliary clearance are better preserved after low-flow anesthesia. Humidity and temperature of the gas was more stable in low-flow than in high-flow anesthesia. The positive effects on postoperative lung function observed in our study may be partly due to the applied low-flow mode, an aspect inadequately represented within the literature about supplemental oxygen.

Abandoning nitrous oxide. We have to point out that we compared 100\% oxygen vs. $30 \%$ oxygen plus 70\% nitrous oxide. Therefore the impact of nitrous oxide and its absence since 1996 on our findings has to be considered. The influence of nitrous oxide on human metabolism and 
outcome parameters has been extensively investigated $(15,16)$. Leslie and co-workers $(17)$ in the POISE trial demonstrated that nitrous oxide was not associated with adverse outcome such as myocardial infarction, stroke, infection, significant hypotension and death. Turan et al. (18) even found a decreased risk of hospital morbidity and 30-day mortality in patients with $\mathrm{N}_{2} \mathrm{O}$ compared to others without, whereas Chen et al. (19) reported $\mathrm{N}_{2} \mathrm{O}$ leading to damage of leucocyte DNA and an increased risk of infection in patients with colorectal surgery. However, nitrous oxide is a fast spreading gas moving in every cavity available such as pleura, bowel or endotracheal tubecuff causing distension (20) an effect not wanted by anesthesiologists and surgeons. Against the background of current scientific evidence the influence of lacking nitrous oxide on our data is negligible, except the prevalence of postoperative nausea and vomiting (PONV).

Postoperative oxygenation, pulmonary morbidity: Changing the anaesthetic ventilation strategy to $100 \%$ oxygen in 1996 , we knew that formation of atelectasis during general anaesthesia was reported to be more pronounced in patients breathing high oxygen concentrations (21), but we had also read the studies of Lampron et al. and Lemaire et al. (22,23), demonstrating no negative effect of pure oxygen ventilation in patients with respiratory failure or severe bacterial pneumonia. Additionally it is known that high oxygen ventilation prevents the lung from hypoxic pulmonary vasoconstriction by neutralizing the Euler-Liljestrand mechanism (24), which may contribute to the beneficial effect, seen in our study. Today, eighteen years after we started with pure oxygen ventilation atelectasis during anaesthesia is still not proven to relevantly affect postoperative outcome in otherwise adequately treated patients. In our study postoperative oxygenation was not negatively affected by pure oxygen ventilation and there was no increased incidence in postoperative pulmonary morbidity, which went for all groups and subgroups. Postoperative hypoxic events even decreased slightly. Our data can be compared with the clinical investigation of Mackintosh and co-workers (25), who applied an intraoperative $\mathrm{FiO}_{2}$ of either 0.3 or 0.9 with and without PEEP and followed up the patients 24 hours after extubation. There was no difference between the groups regarding postoperative oxygenation and the need for additional oxygen. There are also studies with sophisticated approach, such as computer tomography (26), measurement of oxygenation index $\left(\mathrm{PaO}_{2} / \mathrm{FiO}_{2}\right)$ and functional residual capacity $(5,27)$ and meta-analyses of randomized trials $(28,29)$ comparing patients being ventilated with $30 \%, 40 \%, 80 \%$ or $100 \%$ oxygen respectively. None of these studies found any deleterious effect of high oxygen ratio during anaesthetic ventilation. However, especially the conclusions of the meta-analysis of Hovaguimian et al. (29) regarding the lack of pulmonary side 
effects induced a fierce controversial debate (30-33). Hedenstierna and co-workers referred to their own investigations $(31,34)$ and experimental data of van Lam et al. showing that atelectasis increase the incidence of pneumonia (35). However, regarding the clinical relevance, they gave no answer. Meyhoff and et al. (33) criticized that in most studies routine pulmonary examinations have not been performed and, 'adverse effects may be greatly underdiagnosed'. We too can only present parameters of 'real life' routine. Patients after surgery having a normal clinical course and being discharged after the usual length of hospital stay, do not undergo additional diagnostics without justified indication. Observing postoperative oxygenation in all our patients closely for 15 years, more than 13 years of which were with pure oxygen ventilation, we experienced no negative effect of supplemental oxygen at all, though we did not apply any prophylactic measures such as intraoperative recruitment manoeuvre. However, anaesthetic treatment was strictly adjusted, including intra- and postoperative body-temperature conservation, pain therapy, ventilation with PEEP and low tidal volume. Finally we want to point to a routine anaesthetic measure, relaxation, which is nowhere discussed in the literature regarding supplemental oxygen and lung function. Relaxation 'by the clock' is a known risk factor for respiratory complications (36). As pointed to by Donati and co-workers (37) residual paralysis after general anesthesia has an incidence up to $57 \%$, which is appreciated by only $1 \%$ of anesthesiologists. In our patients relaxation was restrictively applied under continuous monitoring (relaxometry).

Surgical site infection (SSI): It is known from experimental and clinical data that wound healing and integrity of gastrointestinal anastomosis significantly depends on tissue oxygenation (38-40). It is also known that nitrous oxide has no effect on SSI (41). Comparing $30 \%$ to $100 \%$ oxygen ventilation within two well comparable groups with identical treatment regarding surgical technique, timing of antibiotics, anaesthetic care incl. temperature control and pain therapy (Table $1,2,3)$, there was a SSI-reduction in all surgical disciplines and subgroups (Table 4). The highest SSI- and consequently reduction-rates occurred in colonic surgery, patients with major abdominal approach, and surgery of peripheral arteries. The incidence of SSI in colonic surgery is high with $20 \%$ (42) to $36 \%$ (43). In their large randomized study in patients with colorectal resection and either $30 \%$ or $80 \%$ oxygen ventilation Greif and co-workers (9) found supplemental oxygen reducing SSI from 11.2 to $5.2 \%$, which is low compared to our findings in similar patients $(22.4$ to $14.7 \%$ ). However, Greif et al. investigated randomized groups excluding patients with minor colon surgery as well as patients with history of fever and infection and patients with serious malnutrition. Our patients were consecutive, with a rate of ASA III/IV patients of $40.5 / 50.6 \%$ 
(1995) and 33.8/60.1\% (1997) respectively, whereas Greif did not include ASA IV patients at all and ASA III patients were 15 - $18 \%$. Our data match with the findings of Belda et al. (44). In their randomized controlled study in patients with elective colorectal surgery they found $24.4 \%$ SSI in patients with $30 \%$ and $14.9 \%$ in patients with $80 \%$ oxygen. In general the discussion about the benefit of high oxygen ratio on surgical site infection is still open, meta-analyses providing conflicting conclusions $(28,45)$.

Postoperative nausea and vomiting (PONV): The scientific debate about the influence of high oxygen ventilation on PONV is controversial $(46,47)$. In our study we compared nitrous oxide (70\%) with no nitrous oxide (100\% oxygen). Leslie et al. in a randomized trial found $\mathrm{N}_{2} \mathrm{O}$ significantly led to an increase in PONV (48). Therefore the reduction of PONV in our study may be rather a consequence of ventilation without $\mathrm{N}_{2} \mathrm{O}$ than ventilating with pure oxygen.

Simplicity and safety: Anaesthesia with pure oxygen ventilation is simple when compared to any kind of air-gas- or nitrous oxide-gas mixture, because only the gas flow (approximately equivalent to patients' oxygen consumption) has to be adjusted. Most importantly it provides a maximum of safety. For one thing confusing oxygen with air or nitrous oxide is impossible. For another thing the pulmonary oxygen storage including residual volume and the physically dissolved oxygen is greatest possible. Physical oxygen is important not by its amount but by its availability (49) which can be crucial in case of cardiopulmonary problems or sudden blood loss with deteriorated circulation.

Study limitations: The assignment of particular data, such as specific co-morbidities, biometric and laboratory data, rate of emergency cases to the individual patient was no longer possible, restricting statistical analysis options. Thus the findings about morbidity parameters, such as SSI and PONV have to be interpreted with care. We present clinical observational data reflecting daily routine when sophisticated diagnostic procedures such as CT or lung function tests are applied only for a justifiable indication.

\section{CONCLUSIONS}

The data presented in this study support the thesis that pure oxygen low-flow ventilation during general anaesthesia is simple and provides a high degree of safety independent of the equipment of the individual department. It is harmless if therapists adhere to strict patient management standards, such as temperature control, optimized pain regimen, guideline-adapted antibiotic 
288 therapy and restrictive use of relaxants and allogeneic blood transfusions. Low-flow anesthesia 289 seems to have a lung protective effect keeping humidity and temperature of the gas stable. 
290 Acknowledgements: We thank Dr. Daniel Bressington, Senior lecturer, Canterbury Christ 291 Church University, UK, for proof-reading this manuscript and lecturer Prasert Sawasdiwipachai, 292 Siriraj hospital for assistance with literature research and data assessment.

293 This study is cordially dedicated to the late Jan Baum, Professor of Anaesthesiology, Damme, 294 Germany, one of the 'fathers' of low flow anaesthesia.

295 Declaration of interests: All authors declare no conflicts of interests

296 Funding: There was no funding at all or other departmental or institutional financial support. 
1. Baum JA, Aitkenhead AR. Low-flow anaesthesia. Anaesthesia 1995;50 Suppl:37-44.

299

2. Baum J, von Bormann B, Meyer J, van Aken $\mathrm{H}$. Pure oxygen as carrier gas in clinical anesthesia. Anaesthesiologie \& Intensivmedizin 2004;45:124-35.

3. Zander R. The oxygen status of arterial human blood. Scand J Clin Lab Invest Suppl 1990;203:187-96.

4. Hedenstierna G, Edmark L. Mechanisms of atelectasis in the perioperative period. Best Pract Res Clin Anaesthesiol 2010;24:157-69.

5. Staehr AK, Meyhoff CS, Henneberg SW, Christensen PL, Rasmussen LS. Influence of perioperative oxygen fraction on pulmonary function after abdominal surgery: a randomized controlled trial. BMC Res Notes 2012;5:383.

6. Canet J, Belda FJ. Perioperative hyperoxia: the debate is only getting started. Anesthesiology 2011;114:1271-3.

7. Qadan M, Akca O. Reassessing the role of supplemental oxygen in the prevention of surgical site infection. Ann Surg 2012;256:902-3.

8. Lutz $\mathrm{H}$, Peter K. [Proceedings: The risks of anaesthesia in surgery (author's transl)]. Langenbecks Arch Chir 1973;334:671-9.

9. Greif R, Akca O, Horn EP, Kurz A, Sessler DI. Supplemental perioperative oxygen to reduce the incidence of surgical-wound infection. N Engl J Med 2000;342:161-7.

10. Bickel A, Gurevits M, Vamos R, Ivry S, Eitan A. Perioperative hyperoxygenation and wound site infection following surgery for acute appendicitis: a randomized, prospective, controlled trial. Arch Surg 2011;146:464-70.

11. Forbes SS, McLean RF. Review article: the anesthesiologist's role in the prevention of surgical site infections. Can J Anaesth 2013;60:176-83.

12. Ferraris VA, Davenport DL, Saha SP, Austin PC, Zwischenberger JB. Surgical outcomes and transfusion of minimal amounts of blood in the operating room. Arch Surg 2012;147:49-55.

13. Schleinzer W, Kasper SM, von Bormann B. [Quality assurance in autologous blood donation. Introduction of a universal German language Site Master File]. Anasthesiol Intensivmed Notfallmed Schmerzther 1995;30:519.

14. Bilgi M, Goksu S, Mizrak A, Cevik C, Gul R, Koruk S, Sahin L. Comparison of the effects of low-flow and high-flow inhalational anaesthesia with nitrous oxide and desflurane on mucociliary activity and pulmonary function tests. Eur J Anaesthesiol 2011;28:279-83.

15. Myles PS, Chan MT, Forbes A, Leslie K, Paech M, Peyton P. Preoperative folate and homocysteine status in patients undergoing major surgery. Clin Nutr 2006;25:736-45.

16. Pasternak JJ, McGregor DG, Lanier WL, Schroeder DR, Rusy DA, Hindman B, Clarke W, Torner J, Todd MM. Effect of nitrous oxide use on long-term neurologic and 
neuropsychological outcome in patients who received temporary proximal artery occlusion during cerebral aneurysm clipping surgery. Anesthesiology 2009;110:563-73.

17. Leslie K, Myles P, Devereaux PJ, Forbes A, Rao-Melancini P, Williamson E, Xu S, Foex P, Pogue J, Arrieta M. Nitrous oxide and serious morbidity and mortality in the POISE trial. Anesth Analg 2013;116:1034-40.

18. Turan A, Mascha EJ, You J, Kurz A, Shiba A, Saager L, Sessler DI. The association between nitrous oxide and postoperative mortality and morbidity after noncardiac surgery. Anesth Analg 2013;116:1026-33.

19. Chen Y, Liu X, Cheng CH, Gin T, Leslie K, Myles P, Chan MT. Leukocyte DNA damage and wound infection after nitrous oxide administration: a randomized controlled trial. Anesthesiology 2013;118:1322-31.

20. Akca O, Lenhardt R, Fleischmann E, Treschan T, Greif R, Fleischhackl R, Kimberger O, Kurz A, Sessler DI. Nitrous oxide increases the incidence of bowel distension in patients undergoing elective colon resection. Acta Anaesthesiol Scand 2004;48:894-8.

21. Rothen HU, Sporre B, Engberg G, Wegenius G, Reber A, Hedenstierna G. Prevention of atelectasis during general anaesthesia. Lancet 1995;345:1387-91.

22. Lampron N, Lemaire F, Teisseire B, Harf A, Palot M, Matamis D, Lorino AM. Mechanical ventilation with $100 \%$ oxygen does not increase intrapulmonary shunt in patients with severe bacterial pneumonia. Am Rev Respir Dis 1985;131:409-13.

23. Lemaire F, Matamis D, Lampron N, Teisseire B, Harf A. Intrapulmonary shunt is not increased by $100 \%$ oxygen ventilation in acute respiratory failure. Bull Eur Physiopathol Respir 1985;21:251-6.

24. Sommer N, Dietrich A, Schermuly RT, Ghofrani HA, Gudermann T, Schulz R, Seeger W, Grimminger F, Weissmann N. Regulation of hypoxic pulmonary vasoconstriction: basic mechanisms. Eur Respir J 2008;32:1639-51.

25. Mackintosh N, Gertsch MC, Hopf HW, Pace NL, White J, Morris R, Morrissey C, Wilding V, Herway S. High intraoperative inspired oxygen does not increase postoperative supplemental oxygen requirements. Anesthesiology 2012;117:271-9.

26. Akca O, Podolsky A, Eisenhuber E, Panzer O, Hetz H, Lampl K, Lackner FX, Wittmann K, Grabenwoeger F, Kurz A. Comparable postoperative pulmonary atelectasis in patients given $30 \%$ or $80 \%$ oxygen during and 2 hours after colon resection. Anesthesiology 1999;91:991-8.

27. Kanaya A, Satoh D, Kurosawa S. Higher fraction of inspired oxygen in anesthesia induction does not affect functional residual capacity reduction after intubation: a comparative study of higher and lower oxygen concentration. J Anesth 2013;27:385-9.

28. Qadan M, Akca O, Mahid SS, Hornung CA, Polk HC, Jr. Perioperative supplemental oxygen therapy and surgical site infection: a meta-analysis of randomized controlled trials. Arch Surg 2009;144:359-66.

29. Hovaguimian F, Lysakowski C, Elia N, Tramer MR. Effect of intraoperative high inspired oxygen fraction on surgical site infection, postoperative nausea and vomiting, and 
pulmonary function: systematic review and meta-analysis of randomized controlled trials. Anesthesiology 2013;119:303-16.

30. Belda FJ, Catala-Lopez F, Greif R, Canet J. Benefits and risks of intraoperative high inspired oxygen therapy: firm conclusions are still far off. Anesthesiology 2014;120:1051-2.

31. Hedenstierna G, Edmark L. Does high oxygen concentration reduce postoperative infection? Anesthesiology 2014;120:1050.

32. Hovaguimian F, Lysakowski C, Elia N, Tramer MR. In reply. Anesthesiology 2014;120:1053-4.

33. Meyhoff CS, Jorgensen LN, Wetterslev J, Rasmussen LS. Intraoperative high inspired oxygen fraction: are there real benefits? Anesthesiology 2014;120:1052-3.

34. Hedenstierna G. Oxygen and anesthesia: what lung do we deliver to the post-operative ward? Acta Anaesthesiol Scand 2012;56:675-85.

35. van Kaam AH, Lachmann RA, Herting E, De JA, van IF, Noorduyn LA, Kok JH, Haitsma JJ, Lachmann B. Reducing atelectasis attenuates bacterial growth and translocation in experimental pneumonia. Am J Respir Crit Care Med 2004;169:1046-53.

36. Grosse-Sundrup M, Henneman JP, Sandberg WS, Bateman BT, Uribe JV, Nguyen NT, Ehrenfeld JM, Martinez EA, Kurth T, Eikermann M. Intermediate acting non-depolarizing neuromuscular blocking agents and risk of postoperative respiratory complications: prospective propensity score matched cohort study. BMJ 2012;345:e6329.

37. Donati F. Residual paralysis: a real problem or did we invent a new disease? Can J Anaesth 2013;60:714-29.

38. Knighton DR, Halliday B, Hunt TK. Oxygen as an antibiotic. The effect of inspired oxygen on infection. Arch Surg 1984;119:199-204.

39. Schietroma M, Cecilia EM, Carlei F, Sista F, De SG, Piccione F, Amicucci G. Prevention of anastomotic leakage after total gastrectomy with perioperative supplemental oxygen administration: a prospective randomized, double-blind, controlled, single-center trial. Ann Surg Oncol 2013;20:1584-90.

40. Kotani N, Hashimoto H, Sessler DI, Muraoka M, Hashiba E, Kubota T, Matsuki A. Supplemental intraoperative oxygen augments antimicrobial and proinflammatory responses of alveolar macrophages. Anesthesiology 2000;93:15-25.

41. Fleischmann E, Lenhardt R, Kurz A, Herbst F, Fulesdi B, Greif R, Sessler DI, Akca O. Nitrous oxide and risk of surgical wound infection: a randomised trial. Lancet 2005;366:1101-7.

42. Yokoe DS, Khan Y, Olsen MA, Hooper DC, Greenbaum M, Vostok J, Lankiewicz J, Fraser VJ, Stevenson KB. Enhanced surgical site infection surveillance following hysterectomy, vascular, and colorectal surgery. Infect Control Hosp Epidemiol 2012;33:768-73.

43. Hubner M, Diana M, Zanetti G, Eisenring MC, Demartines N, Troillet N. Surgical site infections in colon surgery: the patient, the procedure, the hospital, and the surgeon. Arch Surg 2011;146:1240-5. 
44. Belda FJ, Aguilera L, Garcia dIA, Alberti J, Vicente R, Ferrandiz L, Rodriguez R, Company $\mathrm{R}$, Sessler DI, Aguilar G. Supplemental perioperative oxygen and the risk of surgical wound infection: a randomized controlled trial. JAMA 2005;294:2035-42.

45. Togioka B, Galvagno S, Sumida S, Murphy J, Ouanes JP, Wu C. The role of perioperative high inspired oxygen therapy in reducing surgical site infection: a meta-analysis. Anesth Analg 2012;114:334-42.

46. Joris JL, Poth NJ, Djamadar AM, Sessler DI, Hamoir EE, Defechereux TR, Meurisse MR, Lamy ML. Supplemental oxygen does not reduce postoperative nausea and vomiting after thyroidectomy. Br J Anaesth 2003;91:857-61.

47. Rincon DA, Valero JF. [Supplemental oxygen for the prevention of postoperative nausea and vomiting: a meta-analysis of randomized clinical trials]. Rev Esp Anestesiol Reanim 2008;55:101-9.

48. Leslie K, Myles PS, Chan MT, Paech MJ, Peyton P, Forbes A, McKenzie D. Risk factors for severe postoperative nausea and vomiting in a randomized trial of nitrous oxide-based vs nitrous oxide-free anaesthesia. Br J Anaesth 2008;101:498-505.

49. Feiner JR, Finlay-Morreale HE, Toy P, Lieberman JA, Viele MK, Hopf HW, Weiskopf RB. High oxygen partial pressure decreases anemia-induced heart rate increase equivalent to transfusion. Anesthesiology 2011;115:492-8. 


\section{Table 1 (on next page)}

Anesthetic patterns with alternative strategies

Tab 1 - Specifics of intraoperative anesthetic measures in 1995 and from August 1996 until 2009 
Table 1 Specifics of intraoperative Anaesthetic measures in 1995 and from August 1996 until 2009

\begin{tabular}{|c|c|c|}
\hline Anaesthesiological characteristics & 1995 & From $16^{\text {th }}$ August 1996 \\
\hline Ventilator & \multicolumn{2}{|c|}{ Dräger Primus ${ }^{\mathrm{TM}}$} \\
\hline Preoxygenation (Flow, Time) & \multicolumn{2}{|c|}{$5 \mathrm{~L}, 5 \mathrm{Min}$} \\
\hline Tidal volume $(\mathrm{ml} / \mathrm{kgbw})$ & \multicolumn{2}{|c|}{$6-8$ (mild hypercarbia $\left.-\mathrm{pCO}_{2} \approx 45 \mathrm{mmHg}\right)$} \\
\hline PEEP $\left(\mathrm{cmH}_{2} \mathrm{O}\right)$ & \multicolumn{2}{|r|}{$\geq 5$} \\
\hline Inhalation Anaesthetic & \multicolumn{2}{|c|}{ Desflurane; in Infants $\leq 5 \mathrm{Y}$ Sevoflurane } \\
\hline Gas Monitoring: Anaesthetic, $\mathrm{O}_{2}, \mathrm{~N}_{2} \mathrm{O}, \mathrm{CO}_{2}$ & \multicolumn{2}{|c|}{ inspiratory and expiratory (Required by law) } \\
\hline Nitrous-Oxide (\%) & 70 & 0 \\
\hline Flow (I/Min) & $2.5-5$ & $0.2-0.3$ \\
\hline $\mathrm{FiO}_{2}$ & 0.3 & 1.0 \\
\hline $\begin{array}{l}\text { Inspiratory Oxygen (\%; approx.) after } \\
\text { equilibration period }\end{array}$ & 28 & 90 \\
\hline $\begin{array}{l}\text { Expiratory Oxygen (\%; approx.) after } \\
\text { equilibration period }\end{array}$ & 25 & 86 \\
\hline Wash-In Phase (Min) & 5 & 0 \\
\hline Wash-Out Phase (Min) & 5 & 0 \\
\hline Induction, Relaxation, Opiate & $\begin{array}{l}\text { Propofol (Etomidate), } \\
\text { Rocuronium, Fentanyl }\end{array}$ & $\begin{array}{l}\text { Propofol (Etomidate), } \\
\text { Rocuronium, Remifentanil }\end{array}$ \\
\hline Risk of low oxygen supply & Yes & No \\
\hline Readjustment & Yes & No \\
\hline Monitoring - Basic = standard & \multicolumn{2}{|c|}{$\begin{array}{l}\text { ECG, NIBP, Temperature (oesophageal), Pulsoxymetry, } \\
\text { Relaxometry (MSD, UK), Cuff-Pressure }\end{array}$} \\
\hline $\begin{array}{l}\text { Advanced monitoring, selective for: } \\
\text { Laparotomy (all disciplines), thoracotomy, } \\
\text { surgery of the arteries (Aorta, carotid, } \\
\text { subclavian, lower limb), Spine surgery; high } \\
\text { risk patients }\end{array}$ & \multicolumn{2}{|c|}{$\begin{array}{l}\text { Invasive BP, C.I. (invasive and non-invasive) incl. various } \\
\text { calculated hemodynamics, Somatosensory evoked } \\
\text { potentials (SEP) } \\
\text { Hourly blood gas analysis (Radiometer Medical, Bronshoj } \\
\text { Denmark), incl. blood sugar, lactate, cHb, platelet count }\end{array}$} \\
\hline Adjuvant measures - all & \multicolumn{2}{|c|}{ Gastric tube, Thermal blanket - Baer Hugger ${ }^{\mathrm{TM}}$ (incl. PACU) } \\
\hline $\begin{array}{l}\text { Adjuvant measures - all female } \\
\text { - all patients with PONV history }\end{array}$ & \multicolumn{2}{|c|}{$\begin{array}{l}\text { - Dexamethasone } 4 \mathrm{mg} \text { IV during induction } \\
\text { - additional Ondansetron } 16 \mathrm{mg} \text { IV }\end{array}$} \\
\hline Advanced measures & \multicolumn{2}{|c|}{ Central venous catheter, pulmonary artery catheter } \\
\hline Antibiotic prophylaxis (SOP: IL-Nr:1.4-1 & \multicolumn{2}{|c|}{ According to the respective actual guidelines } \\
\hline
\end{tabular}




\section{Table 2 (on next page)}

Surgery during 15 consecutive years

Tab 2 - Characteristics of surgical procedures in 1995 and 1997 
Table 2 Characteristics of surgical procedures in 1995 and 1997

\begin{tabular}{|c|c|c|c|}
\hline Surgical Discipline & Surgical Procedure & $1995\left(\mathrm{FiO}_{2}=0.3\right)$ & $1997\left(\mathrm{FiO}_{2}=1.0\right)$ \\
\hline$\overline{\text { ALL }}$ & & 5,255 & 5,245 \\
\hline \multirow{4}{*}{$\begin{array}{l}\text { General } \\
\text { Surgery }\end{array}$} & $\overline{A L L}$ & 1,322 & 1,351 \\
\hline & Minor & 765 & 838 \\
\hline & Major & 231 & 220 \\
\hline & Colorectal & 326 & 293 \\
\hline \multirow[t]{4}{*}{ Gynaecology } & $\overline{\mathrm{ALL}}$ & 779 & 736 \\
\hline & Minor & 510 & 471 \\
\hline & Major & 189 & 190 \\
\hline & Mamma & 80 & 75 \\
\hline \multirow[t]{4}{*}{ Orthopaedic Surgery } & $\overline{\mathrm{ALL}}$ & 1,769 & 1,749 \\
\hline & Minor & 997 & 990 \\
\hline & Major & 693 & 656 \\
\hline & Spine & 79 & 103 \\
\hline \multirow[t]{5}{*}{ Vascular Surgery } & $\overline{A L L}$ & 1,443 & 1,409 \\
\hline & Minor & 342 & 350 \\
\hline & Aortic & 271 & 244 \\
\hline & Major artery & 630 & 620 \\
\hline & Cerebral artery & 200 & 195 \\
\hline
\end{tabular}

General surgery: 'Major' = gastrectomy, Whipple operation, splenectomy, biliodigestive anastomosis, oesophagus resection, liver surgery, lung surgery; 'Colorectal' = surgery of colon, rectum, sigma; 'Minor' = herniotomy, strumectomy, cholecystectomy, appendectomy, biopsy and minor revisions. Gynaecology: 'Major' = laparotomy, abdominal hysterectomy, vulvectomy; 'Mamma' = all resections of the breast, 'Minor' = endoscopy, biopsy, curette, minor revisions. Orthopaedic Surgery: 'Major' = arthroplasty or major repair of knee, hip, shoulder, polytrauma of the skeleton; 'Minor' = osteosynthesis, removal of material, tendon repair, arthroscopy, nucleotomy, kyphoplasty, minor revisions; 'Spine' = fusion, vertebrectomy, laminectomy, spondylodesis. Vascular Surgery: 'Aortic' = open abdominal and thoracic repair; 'Cerebral' = carotid artery repair (95\%), repair of subclavian or vertebral artery; 'Major artery' = revascularization of peripheral arteries, such as iliac, femoral, popliteal, incl. various bypass procedures, thigh amputation; 'Minor' = varectomy, invasive catheter insertion, pacemaker and port insertion, shunt surgery, minor revisions and amputations. 


\section{Table 3 (on next page)}

Surgical patients during 15 consecutive years.

Tab 3 - Summarized characteristics of surgical patients 1995 and 1997 in \% 
Table 3 Summarized characteristics of surgical patients 1995 and 1997 in \%

\begin{tabular}{|c|c|c|c|c|c|c|c|c|c|c|c|c|c|c|c|}
\hline Surgery & \multicolumn{3}{|c|}{ ALL } & \multicolumn{3}{|c|}{ General } & \multicolumn{3}{|c|}{ Gynaecology } & \multicolumn{3}{|c|}{$\begin{array}{l}\text { Orthopaedic } \\
\text { s/Trauma }\end{array}$} & \multicolumn{3}{|c|}{ Vascular } \\
\hline Parameter & 1995 & $19 \frac{97}{0}$ & $p$ & 1995 & 1997 & $p$ & 1995 & 1997 & $p$ & 1995 & 1997 & $p$ & 1995 & $\begin{array}{l}199 \\
7\end{array}$ & $p$ \\
\hline$\overline{\mathbf{N}}$ & $\begin{array}{l}5,31 \\
3 \\
\end{array}$ & $\begin{array}{l}5,24 \\
5 \stackrel{\mathrm{d}}{\mathrm{d}}\end{array}$ & & 1322 & 1351 & & 779 & 736 & & 1769 & 1749 & & 1433 & $\begin{array}{l}140 \\
9 \\
\end{array}$ & \\
\hline$<15 Y$ & 10.1 & $11 \%$ & \multirow[t]{3}{*}{0.36} & 16.6 & 17.8 & \multirow[t]{3}{*}{0.69} & 7.8 & 9.5 & \multirow[t]{3}{*}{0.23} & 13.5 & 14.6 & \multirow[t]{3}{*}{0.57} & 1.2 & 0.8 & \multirow{3}{*}{$\begin{array}{l}< \\
0.0001\end{array}$} \\
\hline $16-70 Y$ & 78.8 & $76 \frac{5}{3}$ & & 65.2 & 64.6 & & 79.1 & 75.4 & & 79.9 & 78.5 & & 89.9 & 85.2 & \\
\hline$>70 Y$ & 11.1 & 127 & & 18.2 & 17.6 & & 13.1 & 15.1 & & 6.6 & 6.9 & & 8.9 & 14.0 & \\
\hline Female & 47.0 & 48.5 & 0.18 & 47.1 & 49.1 & 0.16 & 100 & 100 & 1 & 37.2 & 39.3 & 0.19 & 30.2 & 32.5 & 0.2 \\
\hline ASA I - II & 42.1 & $\overline{40.3}$ & \multirow[t]{3}{*}{0.33} & 51.1 & 51.0 & \multirow[t]{3}{*}{0.41} & 82.9 & 82.7 & \multirow[t]{3}{*}{0.81} & 46.1 & 41.1 & \multirow[t]{3}{*}{0.12} & 7.0 & 6.9 & \multirow[t]{3}{*}{0.9} \\
\hline ASA III & 32.8 & 325 & & 24.2 & 22.4 & & 13.0 & 12.5 & & 46.9 & 51.1 & & 33.7 & 33.6 & \\
\hline ASA IV & 25.1 & 2.1 & & 24.7 & 26.6 & & 4.1 & 4.8 & & 7.0 & 7.8 & & 59.2 & 59.5 & \\
\hline $\begin{array}{l}\text { Pain- } \\
\text { Catheter }\end{array}$ & 26.2 & 26.7 & 0.72 & 31.8 & 31.3 & 0.8 & 9.4 & 12.2 & 0.63 & 22.9 & 22.6 & 0.86 & 34.0 & 34.7 & 0.71 \\
\hline H-Trans & 17.2 & 16.0 & \multirow[t]{2}{*}{0.60} & 22.5 & 21.3 & \multirow[t]{2}{*}{0.68} & 6.2 & 6.3 & \multirow[t]{2}{*}{0.68} & 20.4 & 18.8 & \multirow[t]{2}{*}{0.68} & 14.6 & 12.6 & \multirow[t]{2}{*}{0.3} \\
\hline A-Trans & 19.7 & 21.4 & & 1.8 & 2.1 & & 0.4 & 0.7 & & 31.4 & 33.5 & & 32.2 & 32.7 & \\
\hline $\mathrm{OP} \leq 1.5 \mathrm{~h}$ & 48.7 & 50.0 & \multirow[t]{2}{*}{0.9} & 55.4 & 58.8 & \multirow[t]{2}{*}{0.68} & 66.0 & 63.0 & \multirow[t]{2}{*}{0.85} & 47.5 & 49.0 & \multirow[t]{2}{*}{0.35} & 36.7 & 35.7 & \multirow[t]{2}{*}{0.9} \\
\hline $\mathrm{OP}>1.5 \mathrm{~h}$ & 51.3 & 50.0 & & 44.6 & 41.2 & & 34.0 & 37.0 & & 52.5 & 51.0 & & 63.3 & 64.3 & \\
\hline
\end{tabular}

Pain-Catheter $=$ regional catheters for postoperative pain relief (epidural, femoral, sciatic, interscalene), H-/A-Trans = homologous/autologous transfusion (any kind) 


\title{
Table 4(on next page)
}

Surgical patients with pure oxygen during 15 years

\author{
Tab \\ 4 - Outcome data of surgical \\ patients 1995 (30\% oxygen) and 1997 (100\% oxygen)
}


Table 4 Outcome data of surgical patients 1995 (30\% oxygen) and 1997 (100\% oxygen)

\begin{tabular}{|c|c|c|c|c|c|c|c|c|c|c|c|c|c|c|c|c|c|}
\hline \multirow[t]{2}{*}{ Surgical group } & \multicolumn{2}{|c|}{$\mathbf{N}$} & \multicolumn{3}{|c|}{ Postop. Hypoxia (\%) } & \multicolumn{3}{|c|}{ U-ICU (\%) } & \multicolumn{3}{|c|}{ SSI (\%) } & \multicolumn{3}{|c|}{ PONV (\%) } & \multicolumn{3}{|c|}{ H-Mortality (\%) } \\
\hline & 1995 & 1997 & 1995 & 1997 & $\mathbf{P}$ & 1995 & 1997 & $\mathbf{P}$ & 1995 & 1997 & $\mathbf{P}$ & 1995 & 1997 & $\mathbf{P}$ & 1995 & 1997 & $\mathbf{P}$ \\
\hline ALL & 5,313 & $5,245_{+}$ & 4.3 & 3.0 & $\begin{array}{c}< \\
0.0001\end{array}$ & 1.1 & 0.9 & 0.18 & 8.0 & 5.0 & $<0.0001$ & 21.6 & 17.5 & $<0.0001$ & 2.1 & 1.6 & 0.088 \\
\hline $\begin{array}{l}\text { GENERAL } \\
\text { SURGERY }\end{array}$ & 1,322 & 1,351 & 3.9 & 2.7 & 0.026 & 0.8 & 0.8 & 0.959 & 10.8 & 6.1 & $<0.0001$ & 3.5 & 19.0 & 0.004 & 2.5 & 1.9 & 0.136 \\
\hline Colorectal & 326 & 293 & 3.4 & 2.7 & 0.643 & $0 *$ & $0 *$ & & 22.4 & 14.7 & 0.014 & 20.6 & 17.7 & 0.377 & 4.3 & 4.1 & 0.902 \\
\hline Major & 231 & 220 & 3.5 & 2.3 & 0.514 & $0 *$ & $0 *$ & & 17.3 & 10.9 & 0.051 & 25.6 & 20.9 & 0.245 & 6.9 & 4.1 & 0.110 \\
\hline Minor & 765 & 838 & 4.1 & 2.7 & 0.114 & 1.4 & 1.3 & & 3.9 & 1.8 & $<0.01$ & 24.2 & 19.0 & 0.011 & 0.4 & 0.5 & 0.796 \\
\hline GYNECOLOGY & 779 & 736 & 2.3 & 2.2 & 0.581 & 0.5 & 0.1 & 0.20 & 8.5 & 5.4 & 0.021 & 21.3 & 16.8 & 0.027 & 0.8 & 0.4 & 0.321 \\
\hline Major & 189 & 190 & 5.8 & 4.2 & 0.473 & 2.1 & 0.5 & 0.175 & 12.7 & 7.9 & 0.124 & 20.1 & 14.2 & 0.128 & 1.6 & 1.1 & 0.391 \\
\hline Mastectomy & 80 & 75 & 3.8 & 4.0 & 0.936 & 0 & 0 & & 13.8 & 8.0 & 0.252 & 23.8 & 18.7 & 0.44 & 2.5 & 0 & 0.168 \\
\hline Minor & 510 & 471 & 0.8 & 0.6 & 0.784 & 0 & 0 & & 6.1 & 4.0 & 0.146 & 21.4 & 17.6 & 0.139 & 0.2 & 0.2 & 0.792 \\
\hline ORTHOPEDICS & 1,769 & 1,740 & 4.5 & 2.6 & 0.003 & 0.6 & 0.4 & 0.357 & 2.1 & 1.5 & 0.224 & 20.6 & 16.5 & 0.002 & 0.5 & 0.4 & 0.632 \\
\hline Spine & 79 & 103 & 6.3 & 3.9 & 0.451 & $0 *$ & $0 *$ & & 1.3 & 1.0 & 0.850 & 31.6 & 21.4 & 0.116 & 2.5 & 1.0 & 0.412 \\
\hline $\begin{array}{l}\text { Major, } \\
\text { Arthroplasty }\end{array}$ & 693 & 656 & 4.6 & 2.3 & 0.020 & 1.0 & 0.3 & 0.112 & 2.7 & 1.8 & 0.264 & 20.5 & 16.9 & 0.093 & 0.7 & 0.6 & 0.801 \\
\hline Minor & 997 & 990 & 4.3 & 2.7 & 0.055 & 0.4 & 0.2 & 0.418 & 1.7 & 1.4 & 0.601 & 20.2 & 15.8 & 0.011 & 0.2 & 0.2 & 0.994 \\
\hline $\begin{array}{l}\text { VASCULAR } \\
\text { SURGERY }\end{array}$ & 1,443 & 1,46 & 5.4 & 4.9 & 0.128 & 2.2 & 1.8 & 0.481 & 12.3 & 7.9 & $<0.0001$ & 21.3 & 17.5 & 0.009 & 5.5 & 4.8 & 0.531 \\
\hline Aorta & 271 & 244 & 8.1 & 6.1 & 0.387 & $0 *$ & $0 *$ & & 6.3 & 3.3 & 0.114 & 18.1 & 14.8 & 0.300 & 5.2 & 4.5 & 0.729 \\
\hline Periph. Arteries & 630 & 620 & 6.5 & 5.5 & 0.446 & 4.4 & 3.7 & 0.511 & 21.9 & 14.7 & $<0.001$ & 25.1 & 20.0 & 0.053 & 7.3 & 6.1 & 0.405 \\
\hline Cerebral Arteries & 200 & 195 & 2.0 & 0.5 & 0.186 & $0 *$ & $0 *$ & & 5.5 & 3.1 & 0.235 & & & 0.151 & 2.5 & 1.5 & 0.498 \\
\hline Minor & 342 & 350 & 3.2 & 2.6 & 0.613 & 1.2 & 1.0 & 0.681 & 3.5 & 2.0 & 0.225 & 17.0 & 13.4 & 0.196 & 0 & 0 & \\
\hline
\end{tabular}

*Patients generally designated for ICU

U-ICU $=$ Unplanned ICU admission, SSI = surgical site (wound) infection, PONV = postoperative nausea and vomiting

H-Mortality = in-hospital mortality (during hospital stay; no follow up) 


\section{Figure 1}

\section{Respirator picture}

Fig 1 - Original display of a Primus ${ }^{\text {TM }}$ Ventilator (Dräger, Lübeck, Germany) during general anesthesia in low-flow pure oxygen anesthesia with Desflurane ${ }^{\mathrm{TM}}$. The picture was made in 1997; the exact date is no longer available. 
insp. exsp.

90

86

पू

$\mathrm{N}_{2} \mathrm{O}$

Q1.

Q

的

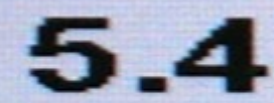

5.2

पs
MAC
Alter: 17
0.7

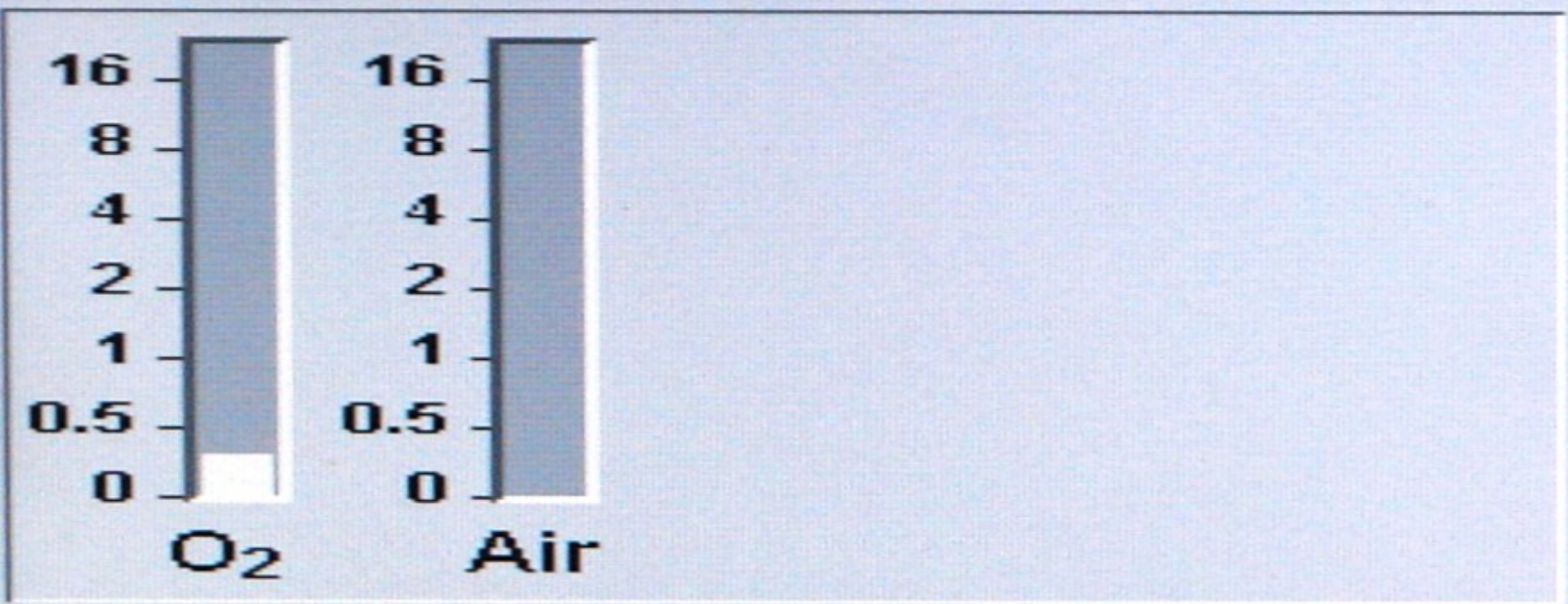

FRISCHGAS

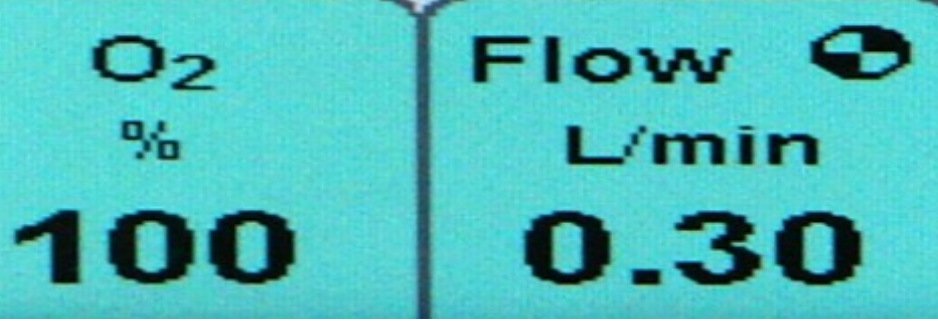




\section{Figure 2}

Course of all patients during 15 years

Fig - 2 Outcome parameters of patients (all) with general, gynecological, orthopedic and vascular surgery between 1995 and 2009. Pure oxygen ventilation was started in August 1996. SSI = surgical site infection, PONV= postoperative nausea and vomiting

Pure oxygen since 1997: All patients with GA $(4,830-5,403 / Y)$

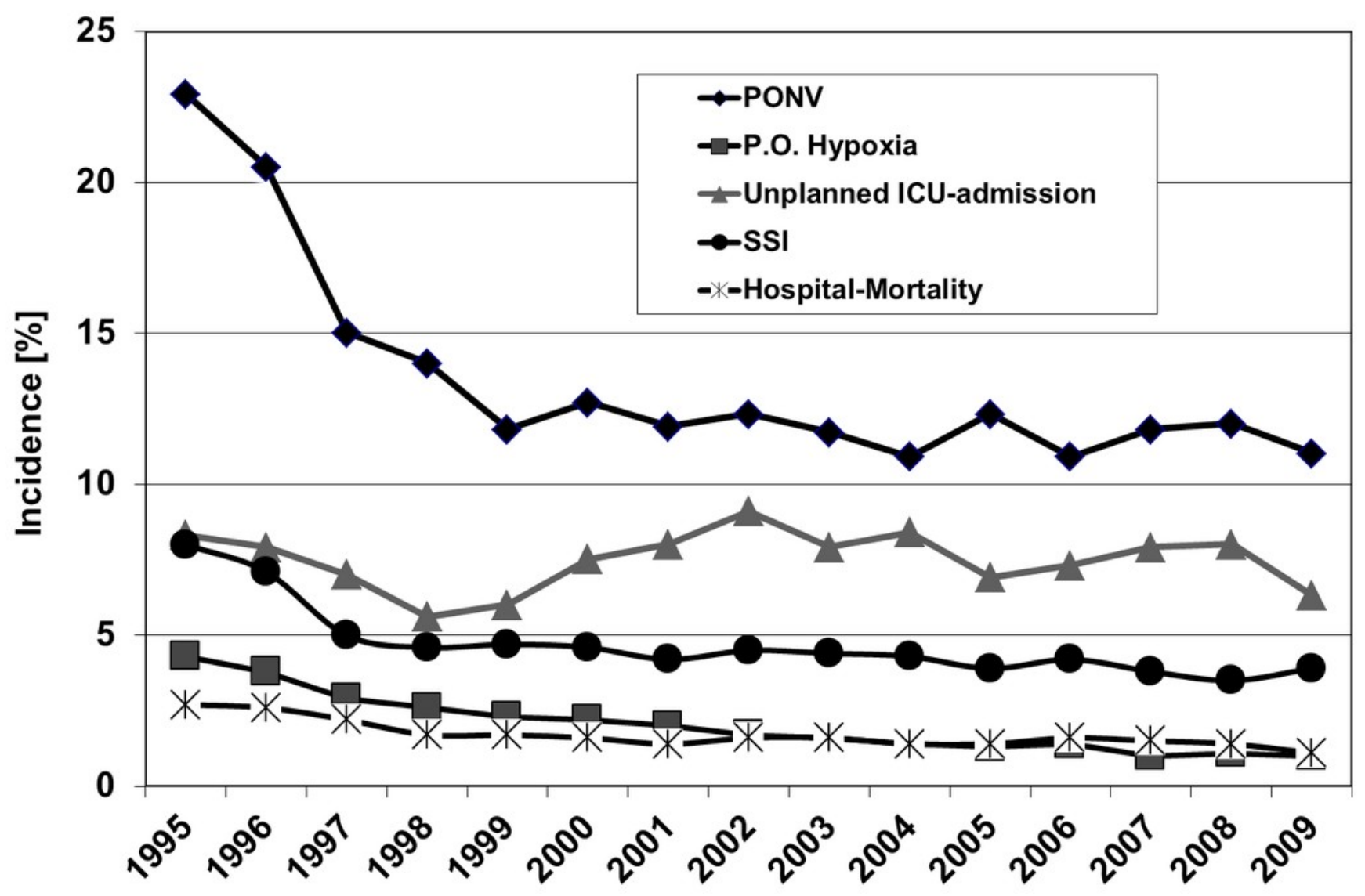




\section{Figure 3}

Oxygen ventilation and hypoxia

Fig 3 - Postoperative hypoxia in patients of four surgical disciplines (all patients) during 1995 - 2009. Pure oxygen ventilation was started in August 1996

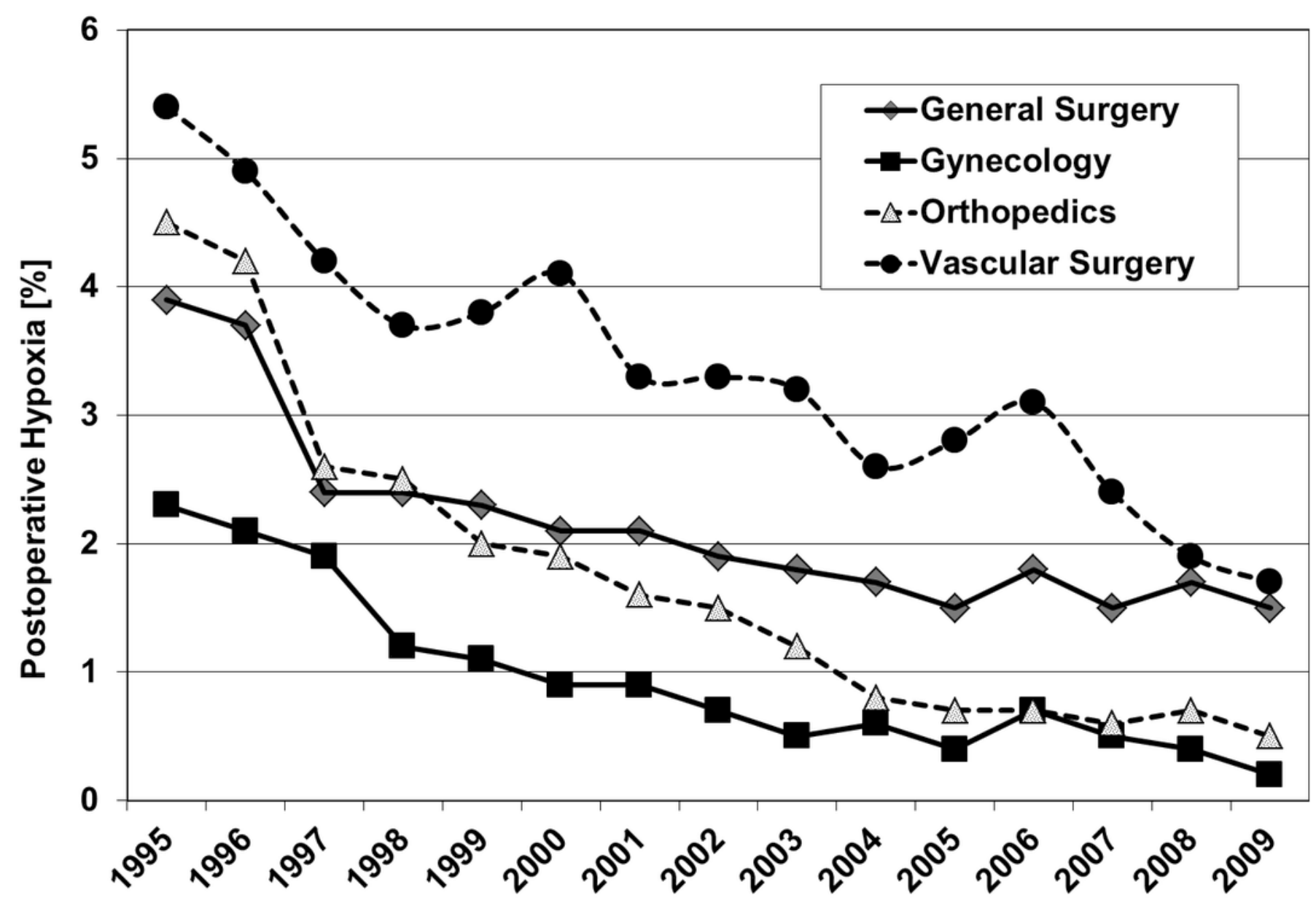




\section{Figure 4}

Oxygen ventilation and postoperative wound infection

Fig 4 - Surgical site infection (SSI) in patients of four surgical disciplines (all patients) during 1995 - 2009. Pure oxygen ventilation was started in August 1996.

\section{Surgical Site Infection (SSI) - All patients}

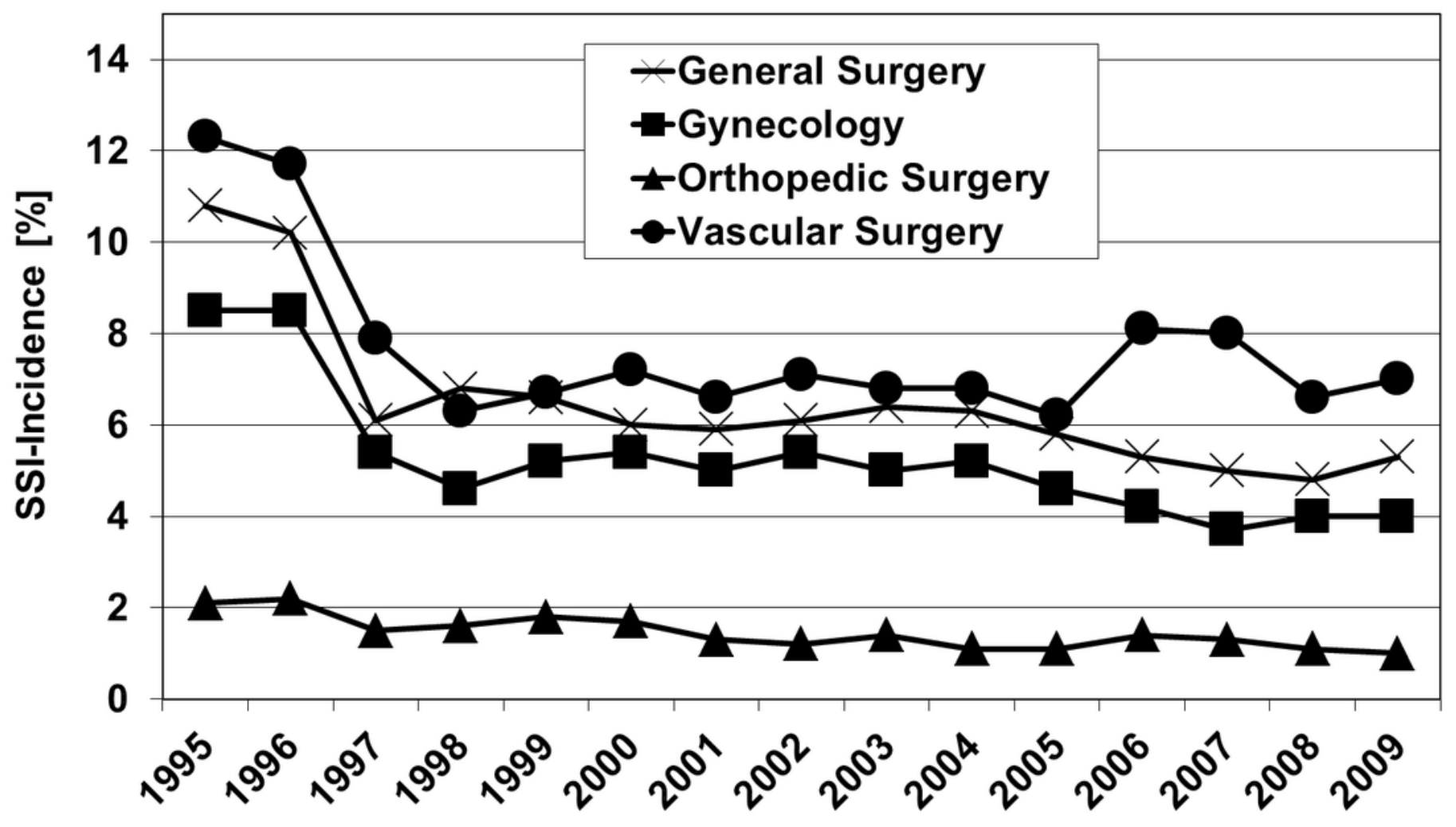

